\title{
Escrever sem palavras: a escrita ideogrâmica em Clarice Lispector
}

To write without words: ideogrammic writing in Clarice Lispector

\author{
Marília Gabriela Malavolta PINHO* \\ Universidade Estadual Paulista (UNESP)
}

RESUMO: Propõe-se, com este artigo, que na crônica Lembrança da feitura de um romance (1970), Clarice Lispector procura igualar, como ideal de escrita, a palavra ao ideograma, o que faz não por meio de afirmação direta (como o fez na conferência Literatura de vanguarda no Brasil), mas por meio de explicações e imagens que aludem às operações do signo ideogrâmico. O método ideogrâmico de composição, tal como este foi explicado e laureado por Ernest Fenollosa e também, posteriormente, por Ezra Pound, contém os argumentos que sustentam tal proposição, ao lado da reunião de evidências do interesse e do conhecimento, por parte de Clarice, seja do ideograma, em si, seja de suas influências na poesia moderna, com o que a escritora teve marcante contato através do grupo intelectual do Professor Francisco Paulo Mendes, quando de sua estadia em Belém do Pará, em 1944.

PALAVRAS-CHAVE: Clarice Lispector. Ideograma. Modernidade.

ABSTRACT: This paper proposes that Clarice Lispector aims to equal words to ideograms as a writing ideal in the short story Lembrança da feitura de um romance (1970). She does not make direct statements (as she did in the conference Literatura de vanguarda no Brasil), but rather provides explanations and images related to operations of ideograms. The ideogrammic composition method, as explained and cherished by Ernest Fenollosa and later by Ezra Pound, provides the arguments for this proposition, along with gathered evidence of Lispector's interest and knowledge both about the ideogram and its influence in modern poetry, which the writer knew in depth through Professor Francisco Paulo Mendes' intellectual circle during her stay in Belém do Pará in 1944.

KEYWORDS: Clarice Lispector. Ideograma. Modernidade.

Recebido em 21 de outubro de 2016. Aprovado em 19 de novembro de 2016.

\footnotetext{
*Universidade Estadual Paulista Júlio de Mesquita Filho (UNESP), Araraquara, Estado de São Paulo, Brasil, pesquisadora em escrita de projeto de Pós-Doutorado. Doutora em Estudos Literários pela Faculdade de Ciências e Letras da UNESP. Mestre em Teoria e História Literária pela UNICAMP. Email: $\underline{\text { mgmalavolta@gmail.com. }}$
} 


\section{Sobre uma rosácea clariciana de convergências: introdução}

A Rosácea das Convergências é um dos subtítulos que compõem o texto de Haroldo de Campos intitulado Ideograma, anagrama, diagrama: uma leitura de Fenollosa, ensaio de abertura da coletânea, por ele organizada, Ideograma: Lógica, Poesia, Linguagem (1977). No trecho correspondente a este subtítulo, o poeta apresenta várias relações e confluências que gravitam a esfera das valiosíssimas contribuições do filósofo e orientalista Ernest Fenollosa (1853 - 1908) à reflorescência e difusão da arte oriental, que culmina com a publicação, por parte de Ezra Pound, de um estudo de Fenollosa que representou, segundo Campos, "uma revolução na literatura moderna" (1977, p. 30). Trata-se do capital ensaio Os caracteres da escrita chinesa como instrumento para a poesia, cuja leitura adequada clama, nas palavras de Haroldo, por um "contexto vivencial" e por um "extratexto cultural", nem sempre prenhes de uma "vinculação direta", de uma "linearidade", mas exemplificadores de uma significativa "rosácea das convergências" (1977, p. 16).

Toma-se, aqui, emprestado este subtítulo a fim de se reunir importantes relações, referências e confluências - vínculos diretos e indiretos, lineares e não lineares - da expressão chinesa na obra e vida de Clarice Lispector. O conduto central desta abordagem será a crônica Lembrança da feitura de um romance, publicada no Jornal do Brasil em 2 de maio de 1970.

\section{Lembrança da feitura de um romance e Literatura de vanguarda no Brasil: os vínculos diretos?}

Declaradamente pouco afeita a questões de ordem teórica, no campo da literatura e das artes, em geral, Clarice Lispector empenhou-se, no início da década de 60 , em estabelecer definição precisa acerca do conceito de Vanguarda, lançando luzes sobre seu próprio fazer literário. Colocando de lado a palavra "vanguarda" no seu sentido europeu, pretensamente universal, de revolução das formas de expressão, a escritora a singulariza, essencialmente, como um novo modo de apreensão do mundo e de compreensão de si mesmo capaz de levar, só então, a uma mudança formal. Segundo informações de Teresa Montero e Lícia Manzo (2005, p. 93), tal definição encontra-se em um ensaio que a autora escreveu para ler, inicialmente, em uma conferência no XI 
Congresso Bienal do Instituto Internacional de Literatura Ibero-Americana, realizado em agosto de 1963, na Universidade do Texas. Muito bem recebido fora e dentro do Brasil, o mesmo conteúdo foi lido também, com poucas modificações, em outros lugares por onde Clarice discorreu, a convite, sobre literatura, foram eles: Vitória, Belo Horizonte, Campos, Brasília e Belém do Pará. Seus originais encontram-se na Fundação Casa Rui Barbosa, junto ao acervo da escritora.

Neste texto, em que o legado do movimento modernista de 1922 é enfaticamente citado, Clarice convoca à linha de frente da literatura brasileira jovens escritores de seu próprio período, clamando por um trabalho, vanguardista, ainda mais profundo e abrangente com a língua portuguesa do Brasil, trabalho apto a resultar em uma operação ideogrâmica da palavra, conforme sugere a escritora:

[...] a atmosfera é de vanguarda, o nosso crescimento íntimo está forçando as comportas e rebentará com as formas inúteis de ser ou de escrever. Estou chamando o nosso progressivo auto-conhecimento de vanguarda. Estou chamando de vanguarda 'pensarmos' a nossa língua. Nossa língua ainda não foi profundamente trabalhada pelo pensamento. 'Pensar a língua portuguesa do Brasil significa pensar sociologicamente, psicologicamente, filosoficamente, linguisticamente sobre nós mesmos. Os resultados são e serão o que se chama de linguagem literária, isto é, linguagem que reflete e diz, com palavras que instantaneamente aludem a coisas que vivemos; numa linguagem real; numa linguagem que é fundo-forma, a palavra é na verdade um ideograma. (LISPECTOR, 2005, p. 106).

Se Clarice não nos deixou maiores esclarecimentos acerca desta afirmação final, que iguala a palavra ao ideograma, no entanto, escreveu, quase dez anos depois, uma crônica em que a operação ideogrâmica parece estar, conforme aqui se propõe, metaforizada em um ideal de escrita, em vinculação direta, portanto, ao que a própria escritora formulou anos antes.

Nessa crônica, Lembrança da feitura de um romance, publicada no Jornal do Brasil em 1970, Clarice Lispector repassa características de seu processo criativo ao condensar, em nove parágrafos, descrições precisas acerca do modo como compôs um romance, cujo título ela não chega a citar. Trata-se de três núcleos ou de três momentos de um processo que se quer uno, integrado. Com efeito, logo no primeiro parágrafo da crônica, antes de divisar esses três momentos, Clarice nos reporta a uma bela imagem de um processo simultâneo, unificado, de escrita criativa: 
Não me lembro mais onde foi o começo, sei que não comecei pelo começo: foi por assim dizer escrito todo ao mesmo tempo. Tudo estava ali, ou parecia estar, como no espaço-temporal de um piano aberto, nas teclas simultâneas de um piano. (LISPECTOR, 1999a, p. 284).

Sequencialmente, ela descreve o seu pathos da escrita, a submissão ao processo de criação, conforme formulou Benedito Nunes.

Escrevi procurando com muita atenção o que se estava organizando em mim, e que só depois da quinta paciente cópia é que passei a perceber. Passei a entender melhor a coisa que queria ser dita. (1999a, p. 285)

Mais adiante, tendo se referido enfaticamente à paciência intrínseca a esse tempo de espera, que é o da sua escrita, Clarice acrescenta: "Além da espera difícil, a paciência de recompor por escrito paulatinamente a visão inicial que foi instantânea. Recuperar a visão é muito difícil” (1999a, p. 285).

Por fim, e já no último parágrafo de seu texto, a escritora refere-se à dificuldade em lidar com a linguagem em meio a esse processo (integrado, simultâneo) de vagaroso desabrochar:

E como se isso não bastasse, infelizmente não sei redigir, não consigo relatar uma ideia, não sei "vestir uma ideia com palavras". [...] o que vem à tona já vem com suas palavras adequadas e insubstituíveis, ou não existe. Ao escrevê-lo, de novo a certeza só aparentemente paradoxal de que o que atrapalha ao escrever é ter de usar palavras. É incômodo. (1999a, p. 285).

Descritivamente, lê-se, nesta crônica, que Clarice refere-se (1) a um ponto de partida visual, instantâneo, captado, (2) que vigorosamente enseja a representação de algo a ser erigido de dentro para fora, (3) em meio à consciência de que as palavras não alcançam plena ou diretamente aquilo que se viu, aquilo que se quer dizer.

Diante do impasse ou do incômodo final, tal como colocado, propõe-se, aqui, que Clarice sugere, como saída, a escrita ideogrâmica. Na crônica, a escritora não referencia tal escrita de modo explícito; trata-se, enfim, de uma proposição deste artigo, apoiada no fato do método ideogrâmico possuir características que muito se harmonizam com o processo criativo de Clarice, e ao mesmo tempo ser núcleo de convergências caras à escritora, conforme se passará a fundamentar. 
Após referir-se ao "incômodo" que é o "ter de usar palavras", a autora melhor se explica e vislumbra uma saída por meio de imagens hipoteticamente substitutas, e resolutivas, desse processo:

É incômodo. É como se eu quisesse uma comunicação mais direta, uma compreensão muda como acontece às vezes entre pessoas. Se eu pudesse escrever por intermédio de desenhar na madeira ou de alisar uma cabeça de menino ou de passear pelo campo, jamais teria entrado pelo caminho da palavra. (1999a, p. 285)

O presente artigo passa a propor, enfim, que, ao longo deste trecho, incluindo seus longos três exemplos finais, é possível encontrar uma alusão à composição ideogrâmica, tal como esta foi explicada e laureada por Ernest Fenollosa, e também, posteriormente, por Ezra Pound.

\section{Lembrança da feitura de um romance à luz do ensaio de Ernest Fenollosa - o extratexto cultural?}

Ernest Francisco Fenollosa, o filósofo e orientalista norte-americano, escreveu um importante ensaio acerca dos caracteres chineses, cujas premissas lançam luzes a esse "incômodo" de linguagem reclamado por Clarice, nos termos em que o condensou na referida crônica. Amplamente, segundo Haroldo de Campos, Fenollosa "como teórico como poeticista -, intuiu os mecanismos profundos de sua arte e foi capaz de prover instrumentalmente as necessidades do futuro" (1977, p. 30). The Chinese written character as a medium for poetry ("Os caracteres da escrita chinesa como instrumento para a poesia") teve seus manuscritos confiados a Ezra Pound por parte da viúva de Fenollosa, Mary MacNeil Scott, que também lhe confiou manuscritos relativos ao Teatro Nô. O ensaio foi editado e publicado por Pound em 1919.

No ensaio, Fenollosa discorre sobre o que considera a supremacia da língua chinesa, que guardaria intensa afinidade com a linguagem poética, de qualquer idioma. Um de seus argumentos basilares consiste no fato dos ideogramas reproduzirem o caráter contínuo do pensamento que veiculam, aproximando-se, assim, do movimento intrínseco à Natureza.

Logo de início, Fenollosa traz uma sentença simples, ocidental, em torno da qual desenvolve sua argumentação: "Homem vê cavalo". Conforme afirma, é a oração à qual se chegaria supondo-se uma situação em que estivéssemos olhando para uma janela, 
vendo um homem que, no mesmo instante, virasse a cabeça e fixasse sua atenção em algo; ao olharmos na mesma direção, veríamos que o homem havia se voltado para um cavalo. Acerca de tal suposição, o filósofo distingue as etapas desse processo natural: ter avistado o homem antes de agir, tê-lo avistado enquanto agia e, por fim, ter avistado o objeto para o qual se dirigiu sua ação. No ato de falarmos, assevera Fenollosa rompemos com a rápida continuidade dessa ação, bem como de sua representação, enquadrando-a em três símbolos fonéticos que não guardam conexão natural entre a coisa e seu signo, como "Homem vê cavalo".

Já o método chinês, exalta o orientalista, guarda a sugestão natural do processo e mantém vivo o elemento de sucessão natural que lhe pertence. Os ideogramas abaixo, correspondentes a "homem", "vê" e "cavalo", trazem, primeiramente,

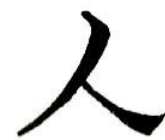

homell

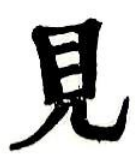

vê

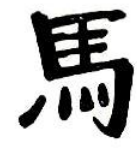

cavalo

o homem de pé sobre duas pernas. Depois, o olho a mover-se pelo espaço: uma figura nítida, representada por pernas a correr embaixo de um olho - o desenho estilizado de um olho e de pernas a correr -, figurações inesquecíveis uma vez que as tenhamos visto. Finalmente, o cavalo sobre suas quatro patas. (1977, p. 122-123)

Segundo enfeixa Fenollosa, a representação oriunda desses signos é "vívida" e "concreta", pelo fato das pernas estarem presentes nos três caracteres, fazendo com que o grupo contenha "algo da qualidade de um quadro contínuo".

Lendo o chinês [conclui o orientalista] não temos a impressão de estar fazendo malabarismos com fichas mentais, e sim de observar as coisas enquanto elas vão tecendo seu próprio destino. (1977, p. 123)

Essa presentificação intrínseca ao signo chinês, capaz de seguir carregando elementos de sentido enquanto esse mesmo sentido se vai ampliando, Fenollosa volta a evidenciar por meio da análise do verso "O sol se ergue a leste", quando, em metáfora musical, identifica como "harmônico" o ideograma que se repete sucessivamente, figurando o movimento natural a que alude. Nos ideogramas que compõem esse verso, o orientalista identifica: 


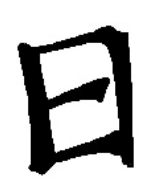

Sol

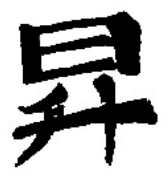

(se) ergue

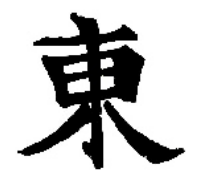

(a) leste

o sol, o brilho, de um lado; do outro lado o signo do leste, formado por um sol entrelaçado aos galhos de uma árvore. E no signo do meio, o do verbo erguer, temos nova homologia: o sol está acima do horizonte, mas, além disto, o único traço reto, no sentido vertical, assemelha-se à linha do tronco, a crescer, do signo da árvore. (1977, p. 149)

Segundo a argumentação de Ernest Fenollosa, mas tomando-se emprestadas palavras que Clarice usou em Lembrança da feitura de um romance, o signo chinês constitui a representação de um "pensamento presente" e de uma "comunicação mais direta", como o quer a escritora. Esse traço de simultaneidade, alcançado ou ambicionado, foi o que Clarice trouxe, é pertinente aqui repeti-lo, no primeiro parágrafo da crônica em questão: “[...] tudo estava ali, ou parecia estar, como no espaço-temporal de um piano aberto, nas teclas simultâneas do piano" (1999a, 284). E talvez tenha sido, conforme o artigo propõe, o que a escritora sugeriu ao final, ao eleger três movimentos como exemplos daquilo que poderia substituir a escrita que lhe é incômoda: desenhar na madeira, alisar a cabeça de um menino e passear pelo campo. Essas escolhas de Clarice consistem em três ações que trazem a continuidade em seu bojo. É como se pudéssemos transformá-las, no rastro dos enunciados utilizados por Fenollosa ("Homem vê cavalo" e "O sol se ergue a leste"), em "A mulher desenha na madeira", "A mulher alisa a cabeça de um menino" e "A mulher passeia pelo campo" e, assim, supondo-lhes os ideogramas correspondentes, evidenciá-las como exemplo de escrita vívida, que carrega um elemento de repetição que melhor a traduz no ato mesmo de sua tecitura ${ }^{2}$.

\footnotetext{
${ }^{2}$ Em uma breve passagem de A paixão segundo $G H$ pode-se ler referência possível à singular grafia chinesa, ideogrâmica. Declarando sua experiência ascética ("Dá-me tua mão, cheguei ao irredutível com a fatalidade de um dobre"; LISPECTOR, 1996, p. 40), que se dá por intermédio da barata, GH confessa sentir no inseto a difícil decifração da grafia do Extremo Oriente: "sinto que tudo isso é antigo e amplo, sinto no hieróglifo da barata lenta a grafia do Extremo Oriente.” (1996, p. 40)
} 


\section{De contextos vivenciais: Clarice Lispector, Fenollosa, Pound e o grupo literário de Francisco Paulo Mendes}

Clarice foi leitora de Ezra Pound, que trouxe aos meios literários, de escritores e estudantes, o método ideogrâmico, bem como dele se valeu. A crônica Dar os verdadeiros nomes, transcrita na íntegra logo abaixo, publicada no Jornal do Brasil em 03 de março de 1973, é uma breve mas contundente glosa poundiana:

Copiei esse trecho de Pound, de um livro que é uma coletânea de artigos, organizada por Norman Holmes Pearson:

- A traição das palavras começa, diz Pound, com o uso das palavras que não atingem a verdade, que não expressam o que o autor deseja que elas digam.

Ezra Pound gostava de citar a resposta dada por Confúcio à pergunta que lhe fizeram sobre o que primeiro the viria ao pensamento como programa de seu Governo, caso fosse escolhido para tal. A resposta foi objetiva, direta: "Chamar o povo e todas as coisas pelos seus nomes próprios e verdadeiros".

Este também é o problema inicial de um artista, comenta Pearson. "Artistas são as antenas da raça", afirmou Pound. "A única coisa que você não deve fazer é supor que quando algo está errado com as artes, isso é um erro artístico somente. Quando um dado harmônico falha, isso deve tornar defeituoso o sistema inteiro." "A beleza é difícil", repete Pound em Cantos. (1999a, p. 453).

Recentemente, em 14 de novembro de 2015, em coluna publicada no jornal $O$ Estado de S. Paulo, o escritor e jornalista Sérgio Augusto relembra de ter visto, durante entrevista realizada com a escritora, em 1974, junto à equipe do Pasquim, o quão grifada era a edição que Clarice tinha de "Escritores em Ação". Ezra Pound é um dos entrevistados dessa coletânea.

[...] Enquanto os demais emissários do Pasquim lhe faziam perguntas, Ivan Lessa e eu, bem posicionados no chão, ao lado de uma estante, arrumamos um jeito de, sorrateiramente, xeretar as anotações que ela fazia em seus livros. O mais grifado e anotado era aquela antologia de entrevistas da Paris Review (Escritores em Ação), que a Paz e Terra traduzira seis anos antes. Clarice, quem diria, nutria enorme curiosidade sobre o que seus colegas pensavam do ofício de escrever.

$\mathrm{Na}$ longa entrevista concedida por Pound, figuram muitas colocações de linguagem e de trabalho literário afins a concepções ou convicções de escrita e de linguagem de Clarice, apresentadas por meio de entrevistas e de sua produção. O poeta, 
por exemplo, quando perguntado sobre o modo como planeja a escrita de um Canto, responde ser o "o que" mais importante que "o como". "Trabalha-se, creio eu, no que a vida nos proporciona. Nada sei acerca de método". (COWLEY, 1982, p. 135) Pound fala, também, em "uma maneira mais natural de escrever". Sobre os meios de comunicação então modernos, afirma "sofrermos do uso da linguagem a ocultar o pensamento e a impedir todas as respostas diretas e vitais". Retoma Confúcio ao asseverar que "a má linguagem está destinada a fazer um mal governo". (1982, p. 149)

$\mathrm{Na}$ entrevista, Ernest Fenollosa é citado em dois momentos. No primeiro deles, quando Pound responde apenas que seu trabalho de tradução das Trachinae provém da leitura das peças Fenollosa Noh; e mais adiante, quando o entrevistador lhe pergunta acerca dos trabalhos que lhe representaram grandes impulsos, grandes estímulos ocasião em que é ressaltado o impacto de modernidade advindo com o ensaio do filósofo sobre os caracteres chineses.

Entrevistador: Suponho que seu interesse, no sentido de que as palavras fossem cantadas, foi estimulado particularmente pelo estudo da Provença. Acha, talvez, que sua descoberta da poesia provençal constitui sua maior "brecha"? Ou, talvez, tenham sido os manuscritos de Fenollosa?

Pound: O provençal começou a interessar-me desde muito cedo, de modo que não constituiu, na verdade, uma descoberta. O Fenollosa foi uma rajada de vento - e a gente lutava contra a própria ignorância. Tinha-se conhecimento íntimo das notas de Fenollosa e a ignorância de uma criança de cinco anos. (1982, p. 146)

Por meio da pergunta seguinte, o poeta esclarece sobre como coube a ele a edição e a publicação do Ensaio Caracteres da escrita chinesa como instrumento para a poesia.

Entrevistador: De que modo Mrs. Fenollosa veio a descobri-lo?

Pound: Bem, eu a conheci em casa de Sarojini Naudu, e ela me disse que Fenollosa tinha vivido em oposição a todos os professores e academias, e que ela vira alguns de meus escritos e achava que eu era a única pessoa que poderia terminar aquelas notas como Ernest teria gostado que se fizesse, Fenollosa percebeu o que precisava ser feito, mas não teve tempo de terminar seu trabalho. (1982, p. 146)

Circundando a rosácea das convergências, tem-se ainda que, a partir do ano de 1898, 
Fenollosa começou a tomar aulas de representação e canto Nô, reencetando um esforço iniciado no começo dos anos 80. Examinado pelo septuagésimo Minoru Umekawa, a figura central da revivescência dessa vetusta arte teatral, Fenollosa foi considerado habilitado a cantar com intérpretes japoneses. Uma honra insigne, especialmente para um não-nativo. (1977, p. 24)

O orientalista traduziu a peça Sotoba Komachi, presente no volume publicado em 1916, "Noh" or Accomplishment: A Study of the Classical Stage of Japan, with Ezra Pound, London: Macmillan and $\mathrm{Co}^{3}$. Uma versão moderna desta mesma peça - eis a convergência a que se aludiu - foi traduzida por Clarice. André Luís Gomes, em Clarice em cena. As relações entre Clarice Lispector e o teatro, na apresentação e análise de traduções dramatúrgicas realizadas, geralmente, por Clarice e Tati Moraes, pontua:

A peça moderna japonesa, Sotoba Komachi, de Yukio Mishima, de 1952, parece ter sido traduzida apenas por Clarice Lispector, se levarmos em consideração tanto o original datilografado, ao qual tive acesso, quanto o registro no SBAT em que consta apenas o nome da autora. Nesses documentos, não há nenhuma indicação da data da tradução e nem da língua a partir da qual Lispector traduziu a peça de Mishima, escrita em um ato. (GOMES, 2007, p. 86)

Acrescente-se a tudo isto o fato de que Clarice, em 1944, logo após publicar seu primeiro romance, Perto do coração selvagem, mudou-se para Belém do Pará, acompanhando o marido em incumbência diplomática. Lá permaneceram por seis meses, hospedados no Hotel Central, em cujo Café intelectuais reuniam-se diariamente em torno do Professor de Literatura Francisco Paulo Mendes do Nascimento, por quem Clarice nutriu grande admiração e amizade. Segundo Benedito Nunes, que a escritora conheceria anos mais tarde, na década de 60 apenas (e por meio do Professor), Mendes foi um verdadeiro fazedor de poetas, tendo impulsionado Ruy Barata, descoberto Plínio Abreu e Mário Faustino - admirador e tradutor conhecido da obra de Pound. O primeiro livro de Mário Faustino foi apresentado à crítica por Mendes, que, de modo entusiasmado, o prefaciou. Em Belém, o professor formou mais de uma geração de intelectuais, atentos e devotos às suas opiniões, seguidores de seu juízo crítico. Mendes,

\footnotetext{
${ }^{3}$ Segundo Jean-Paul Georges Potet, "Among the papers 'bequeathed' to Ezra Pound translations of Noh plays with introductory chapters. Ezra Pound endeavoured to turn the plays into poetical English. Their list is fairly long: Aoi no eu [...] Kumasaka, Matsukaze [...], Sotoba Komachi, [...]. Ezra Pound's edition was published in 1916 under the title Noh or accomplishment." (POTET, 2015, P. 37)
} 
que dirigiu o Suplemento Literário da Folha do Norte, entre os anos de 46 e 52, liderou o grupo de literatos com o qual Clarice conviveu, e em meio ao qual já circulavam as novidades vanguardistas do Concretismo, representadas pelos irmãos Campos e por Décio Pignatari, e da moderna poesia europeia, representada por Mallarmé, Ernest Fenollosa, Ezra Pound, Rainer Maria Rilke e T. S. Eliot.

Tantos e consolidados predicativos fizeram do Professor Mendes um grande formador, para além das salas de aula. Dono de uma "tremenda capacidade argumentativa", Nunes registra que ele deixou verdadeiros "herdeiros espirituais" tendo formado duas gerações de intelectuais, posteriormente amigas entre si. Uma, a mais velha, fora composta principalmente pelos escritores Ruy Barata, Paulo Plínio Abreu, Rui Coutinho, Raymundo Moura, Cléo Bernardo e Sylvio Braga. À outra, mais nova, pertenceram Benedito Nunes, Max Martins, Haroldo Maranhão, Alonso Rocha, Jurandir Bezerra, Cauby Cruz e Mário Faustino (2001, p.16).

[...] praticou ele, de boca principalmente, a crítica de poesia, para o ouvido de seus mais diretos interlocutores: Ruy Barata, Paulo Plínio Abreu, Mário Faustino, Max Martins, e eu mesmo, quando tentei, em vão, ser poeta - sob o fundo da experiência de leitura dos autores que nos deu a conhecer e em que se sustentou o espírito comum das duas gerações reunidas em torno dele - para citar alguns de que me lembro imediatamente, Antero de Quental, Cecília Meireles, Valéry, Rilke e Fernando Pessoa, dentre os poetas; Mauriac, Julien Green, Alain Fournier, Kafka, Bernanos, dentre os ficcionistas; Kierkegaard, Paul Landsberg, Jacques Maritain, Berdiaeff, Sartre, Gabriel Marcel, Karl Jaspers e Martin Heidegger dentre os filósofos. (2001, p.21)

Fora dos espaços destinados às aulas regulares, tais formações se davam, por excelência, no Café Central. Na recordação de Nunes, tal Café era, para Mendes, "sua sala de visita. Ali discutia, lia, debatia ideias e recebia os amigos”. (2001, p. 23) 
Figura 1: Imagens do Hotel Central, onde aconteciam os encontros literários em torno de Francisco Paulo Mendes, e onde Clarice se encontrava hospedada.

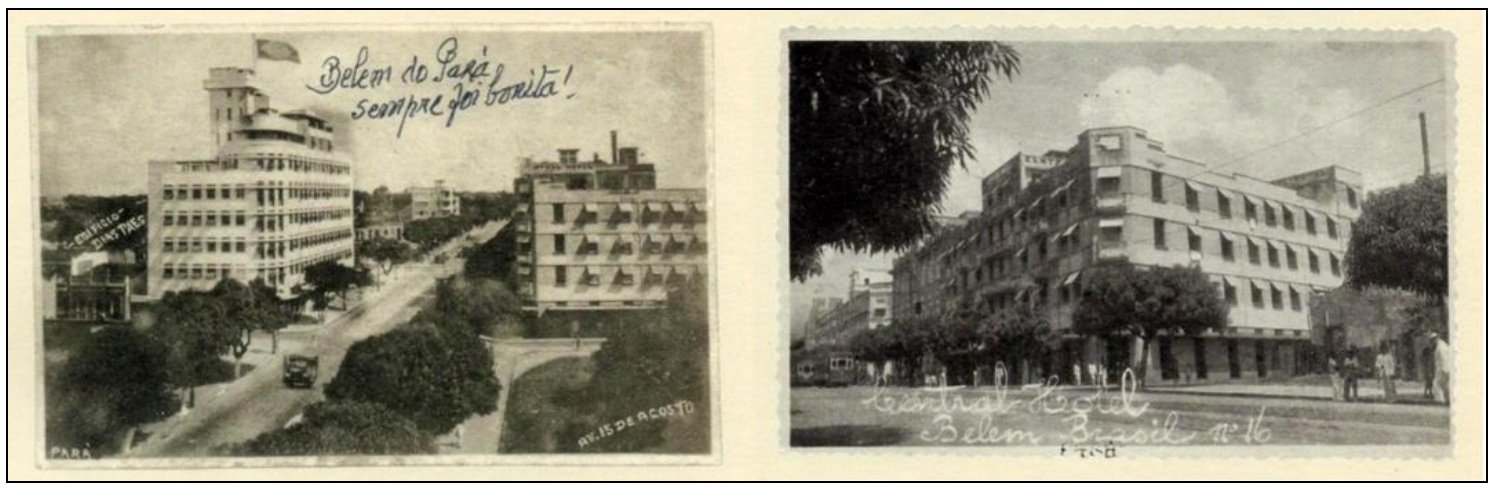

Fonte: "O Amigo Chico, fazedor de poetas", coletânea de textos, organizada por Benedito Nunes, que homenageiam o Professor Francisco Paulo Mendes (2001, p.13).

Francisco Mendes, conforme Clarice conta, em carta, ao amigo Lúcio Cardoso, emprestou-lhe os Cahiers de Malte, de Rilke, e trechos de Proust:

Encontrei aqui pessoas muito interessantes. Paulo Mendes é professor de literatura, mas não um didático. Tem grande biblioteca, conhece um bocado de coisas, mas não ficou [.] sobre a cultura, é muito inteligente. É ótimo falar com ele sobre livros dos quais a gente gosta. Ele me emprestou os Cahiers de Malte, de Rilke, e pedaços escolhidos de Proust. Ele falou de você de um modo que eu gostei de ouvir. (LISPECTOR, 2002, p.42)

Em outra carta a Lúcio, datada de julho de 44, quando já estava fora de Belém, Clarice recomenda enfaticamente o Professor:

Lúcio, vou lhe pedir de novo para que você se interesse para que Paulo Mendes, de Belém, vá ao Rio fazer algumas conferências sobre Antero de Quental ou algum outro assunto. Sei que você gostará dele, sei que ele gostará de você. Se o Ministério da Educação pudesse fazer alguma coisa... Vou repetir seu endereço: F. Paulo Mendes, Vila Amazônia, Passagem Mac-Dowell, 25 - Belém, Pará. (2002, p.48)

Clarice volta a escrever sobre Francisco Mendes muitos anos mais tarde, em dois momentos da década de 70, o que parece corroborar o magnetismo com o qual tanto fora laureado o Professor, bem como a extensão, ou profundidade, da admiração ou influência que ele exercera sobre a jovem escritora.

$\mathrm{Na}$ crônica publicada em $1^{\circ}$ de abril de 1972 , Minha próxima e excitante viagem pelo mundo, a autora, ao final de um roteiro jocosamente apenas imaginado, escreve: 
E enfim voltarei ao Rio. Antes darei um pulo a Belém do Pará, para rever os meus amigos Francisco Paulo Mendes, Benedito Nunes (qual é o endereço deles? Por favor me escrevam) e tantos outros importantes para mim. Eles, vai ver, já me esqueceram. Eu não esqueci deles. Em Belém já passei seis meses, muito felizes. Sou grata a esta cidade. (1999a, p.409)

No romance Um sopro de vida, escrito entre 1974 e 1977, Ângela Pralini, no fim da obra, fala em "pessoas desaparecidas”, e Francisco Mendes é novamente lembrado:

Pessoas desaparecidas. Onde estão? Quando alguém souber delas telefonem para a Rádio Tupi. Cadê o desaparecido Francisco Paulo Mendes? Morreu? Me abandonou, achou que eu era muito importante... (LISPECTOR, 1999b, p.143).

Em 1976, quando entrevistada por Marina Colasanti, Affonso Romano de Sant'Anna e João Salgueiro, volta a se referir a Francisco Mendes, e como seu professor de literatura:

Eu só li Sartre, só ouvi falar de Sartre na época de O lustre, em Belém do Pará.

ARS: O Sartre já era popular em Belém do Pará? Eu digo isso porque o Benedito Nunes é de lá.

Eu tive um professor de literatura que buscava os livros da Europa, e não do Rio. Era o Francisco Paulo Mendes, do mesmo grupo do Benedito Nunes. (SANT'ANNA e COLASANTI, 2013, p. 224)

Com a leitura do texto Literatura de vanguarda no Brasil, já referido anteriormente, no qual a palavra é igualada a um ideograma, Clarice apresentou-se na Universidade Federal do Pará, em 1975, em evento organizado por Nunes e Mendes.

Figura 2: Registros do emocionado reencontro entre Clarice Lispector e Paulo Mendes, em 1975, em Belém do Pará.
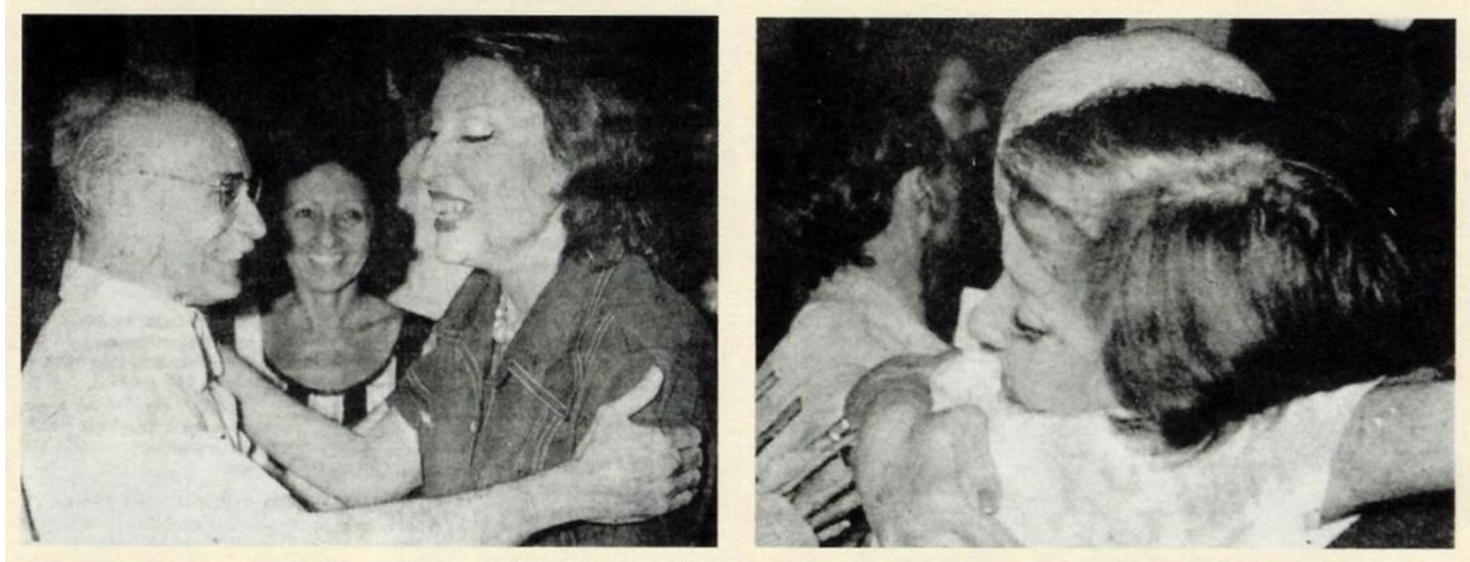

Fonte: "O Amigo Chico, fazedor de poetas" (2001, p. 88). 
De volta a Ernest Fenollosa e Ezra Pound, Benedito Nunes, no ensaio Encontro em Austin, relembra a influência exercida por ambos na poesia moderna, no que diz respeito a elementos da cultura chinesa. Nunes fala em "retrojeção da cultura intelectual e espiritual do Extremo Oriente na europeia, canalizada por Pound e Fenollosa para a poesia no tempo de sua modernidade". (2009, p. 309)

O escritor Max Martins, um dos discípulos de Francisco Paulo Mendes, e também grande amigo de Benedito Nunes, teve Ezra Pound e Ernest Fenollosa como dois de seus autores de cabeceira, ao lado de outras obras de referência oriental, como o I Ching. Conta o jornalista Elias Pinto, em texto publicado em fevereiro de 2009, que em uma das inúmeras e longas conversas que teve com o escritor, pediu-lhe, certa vez, que traçasse um roteiro de sua formação poética, de seus livros, "de seus santos de cabeceira, 'ab ovo', desde o berço". O jornalista lembra que a resposta de Max compôs sua coluna publicada, entre 1990 e 1991, no Jornal “A província do Pará”. É bastante oportuno transcrever, aqui, a vasta e coesa lista de Max, que inclui Fenollosa, no que deixa entrever as influências recebidas pelo Professor Mendes e no que amplia a lista rapidamente relembrada por Nunes, conforme transcrito anteriormente.

No princípio, foi Casemiro de Abreu, os poetas românticos brasileiros e portugueses das velhas antologias. Depois veio o 'Cartas a um Jovem Poeta', de Rainer Maria Rilke, o primeiro presente recebido do professor Francisco Paulo Mendes e cujo exemplar muitos anos depois passei às mãos merecedoras do poeta Age de Carvalho. Depois vieram Carlos Drummond, Jorge de Lima, Murilo Mendes, Manuel Bandeira, Fernando Pessoa, Camões, Homero, Mário Faustino, Dylan Thomas, Rimbaud, Baudelaire, Octavio Paz, Mallarmé, Paul Celan, Henri Michaux, René Char, Bashô, Cummings, Blaise Cendrars, Kaváfis, Maiakóvski, Jorge Luis Borges, Robert Stock, García Lorca, Lautreamont, Ungaretti, Trakl, Blake, André de Bouchet, as vanguardas, o Concretismo.

E Guimarães Rosa ('Grande Sertão: Veredas'), D. H. Lawrence, Henry Miller, Henry Thoreau, Clarice Lispector, Dostoiévski, Thomas Hardy ('Judas, o Obscuro'), Kazantzákis, Hermann Hesse, Romain Rolland, Thomas Mann, Flaubert, Malcolm Lowry, Hermann Broch, 'Em Busca do Tempo Perdido', de Proust, o 'Dom Quixote', Melville, Shakespeare, Mircea Eliade, Chuan-Tzu, o Zen-Budismo, 'I Ching', 'Lao-Tzu', 'O Livro Tibetano dos Mortos', o 'Bhagavad-Gita', a Bíblia.

E Aristóteles, Platão, Nietzsche, Heidegger ('Acheminement Vers la Parole, Hölderlin y la Esencia de la Poesia'), Derrida, Gilles Deleuze, Todorov, Pound ('ABC da Literatura' e 'A Arte da Poesia'), Valéry 
('M. Teste'). E Damaso Alonso, Carlos Busoño, Roman Jakobson, Auerbach, Roland Barthes, Georges Bataille, T. S. Eliot, Walter Benjamin, George Steiner, os Manifestos Surrealistas, Max Bense, Benedito Nunes, José Guilherme Merquior, Antonio Candido, Ernest Fenollosa, Haroldo de Campos, Jean Starobinski, Saussure, Leo Spitzer. Isso não é receita para jovens poetas, o que eles deveriam ler etc. É o meu caso e só. Mas acho que um poeta de hoje deve palmilhar por aí. Creio que esse é, pelo menos, o cerne de uma compreensão e de um amor pela poesia. 4

A influência oriental na composição poética de Max Martins pode ser vista, sobretudo, nas obras Para ter onde ir e A fala entre parêntesis, escrita, esta, em parceria com o amigo Age de Carvalho, à moda da renga. O primeiro livro é todo tecido a partir dos hexagramas do clássico chinês I Ching, o Livro das Mutações, enquanto o segundo exercita, mais livremente, a composição japonesa conhecida como jogo da renga, que significa, literalmente, uma cadeia de poemas. As duas obras contaram com ricos comentários de um dos principais estudiosos de Clarice Lispector, e também discípulo do Professor Paulo Mendes, Benedito Nunes. Em 1982, Nunes escreveu o prefácio, intitulado Jogo Marcado, de A fala entre parêntesis, livro, inclusive, dedicado ao crítico e sua esposa, Maria Sylvia.

${ }^{4} \mathrm{Em}$ http://ronaldofranco.blogspot.com.br/2009/02/max-e-seus-santos-de-cabeceira-elias.html. Data do acesso: 30 de setembro de 2016. 
Figura 3: Os amigos Paulo Mendes na companhia dos amigos Max Martins, Benedito Nunes e Maria Sylvia.

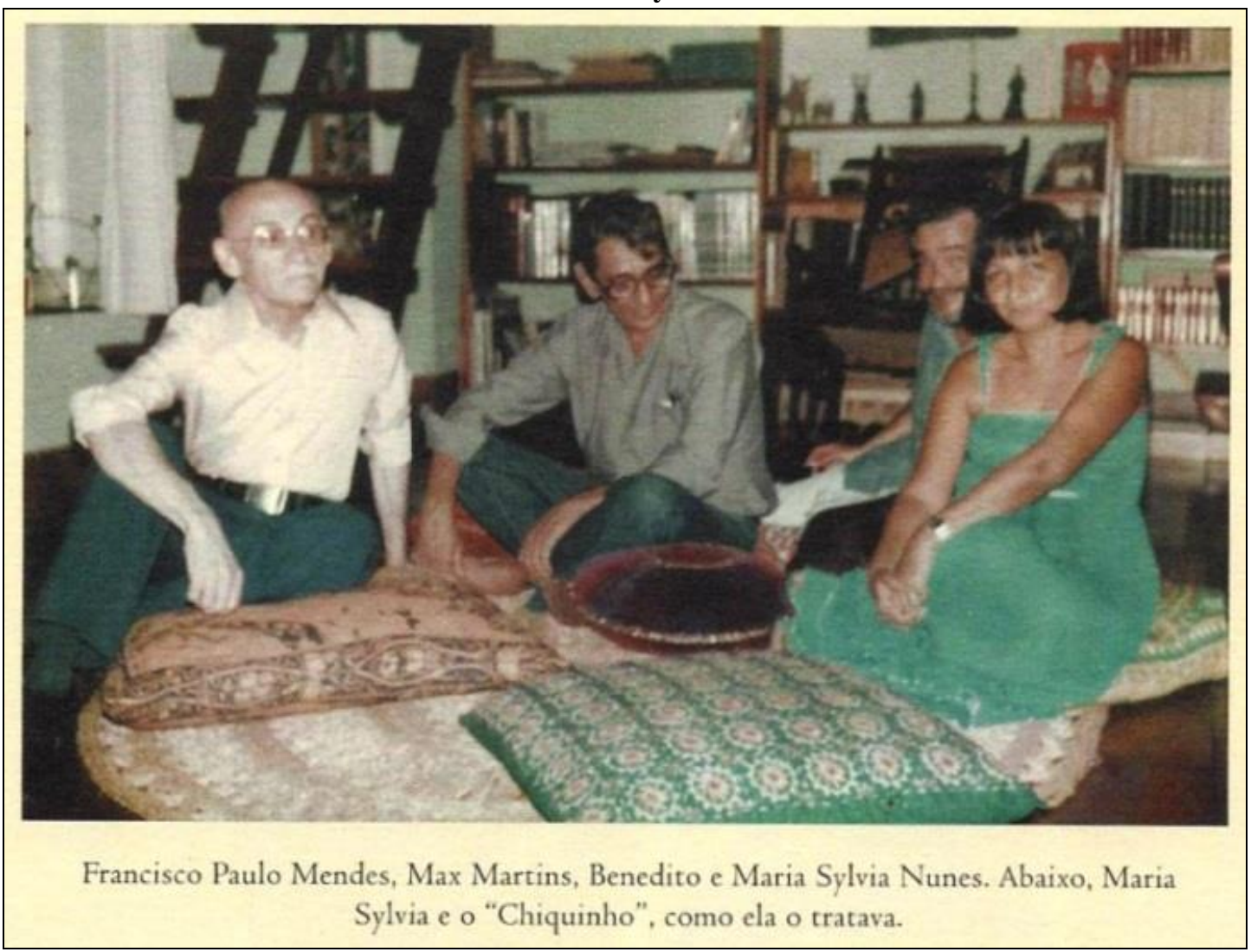

Fonte: "O amigo Chico, fazedor de poetas" (2001, p. 31).

\section{Considerações finais}

Conforme sintetizou Benedito Nunes no ensaio Reflexões sobre o moderno romance brasileiro, a literatura de linhagem moderna traz em seu bojo a consciência preliminar das limitações da linguagem no que diz respeito a uma direta e instantânea relação com a realidade, fazendo recair sobre essa mesma linguagem o dever de ligar o romance ao real (2009, p. 142). Visceralmente praticada por Clarice Lispector, a literatura prenhe dessa consciência faz da linguagem - sublinhada em suas limitações e impossibilidades de nomeação - um de seus temas constantes. Se, por um lado, a crônica Lembrança da feitura de um romance é um dos exemplos vários da tematização dessa aporia encarnada na palavra é, por outro, exemplo raro, senão único, da metaforização de uma saída pela via da operação ideogrâmica, o que a escritora havia já sinalizado, não ficcionalmente, mas teoricamente, na conferência Literatura de vanguarda no Brasil. Assim, lançando luzes para abordagem que também considere o 
signo oriental, espera-se que o presente artigo possa contribuir com os ricos estudos acerca da questão da linguagem na obra da escritora, escorados, em sua maioria, na moderna filosofia da linguagem, que tem em Wittgenstein e Heidegger dois de seus expoentes máximos.

Ao lado de múltiplas referências, reitera-se, acerca dos contatos da escritora com o método ideogrâmico de compor, conclui-se que a crônica em questão revela a metaforização deste método, e, em decorrência disto, revela ainda uma importante relação de filiação entre a prosa (poética) praticada por Clarice e a poesia moderna tal como fora canalizada por Fenollosa e Pound. Nessa direção, conclui-se também que há possibilidades de a escritora primeiramente ter tocado nessas questões, direta ou indiretamente, ainda no início de seu ofício, na década de 40, quando do profícuo convívio com o grupo intelectual do Professor Francisco Paulo Mendes do Nascimento, em Belém do Pará.

\section{REFERÊNCIAS}

CAMPOS, Haroldo (Org). Ideograma: lógica, poesia e linguagem. Tradução Heloysa de Lima Dantas. São Paulo: Cultrix, 1977.

COWLEY, MALCOLM (Org). Escritores em ação: as famosas entrevistas à "Paris Review, por Alberto Moravia e outros. Tradução Brenno Silveira. 2a ed. Rio de Janeiro: Paz e Terra, 1982.

GOMES, André Luís. Clarice em cena. As relações entre Clarice Lispector e o teatro. Brasília: Editora UNB, 2007.

LISPECTOR, Clarice. A paixão segundo G. H. (edição crítica coordenada por Benedito Nunes). 2 ed. Madrid/Paris/México/Buenos Aires/São Paulo/Rio de Janeiro: ALLCA XX, 1996 (Coleção Archivos).

A descoberta do mundo. Rio de Janeiro: Rocco, 1999a.

2005.

Outros escritos (org. Teresa Montero e Lícia Manzo). Rio de Janeiro: Rocco,

. Um sopro de vida. Rio de Janeiro: Rocco, $1999 \mathrm{~b}$.

Correspondências. Rio de Janeiro: Rocco, 2002.

NUNES, Benedito. A clave do poético. São Paulo: Companhia das Letras, 2009 
(Org.). O amigo Chico fazedor de poetas. Belém / Pará: Secult, 2001.

POTET, Jean P. G. Yeats and Noh. United States of America: Lulu Press, Inc, 2015.

POUND, Ezra. ABC da literatura. 12ed. São Paulo: Cultrix, 2013.

SANT'ANNA, Affonso de R. e COLASANTI, Maria. Com Clarice. São Paulo: Editora Unesp, 2013. 